\title{
A Retrospective Study of Infantile Hemangiomas: Demographic and Clinical Characteristics at Hera General Hospital, Makkah, Saudi Arabia
}

HO Al otaibi ${ }^{1}$, MI Fatani ${ }^{2}$, MM Alshareef ${ }^{3}$, MA Khalifa ${ }^{2}$ and SS Mohammed ${ }^{4}$

${ }^{1}$ King Khalid University Hospital, Riyadh, Saudi Arabia

${ }^{2}$ Hera General Hospital, Makkah, Saudi Arabia

${ }^{3} \mathrm{Umm}$ AL-qura university, Makkah, Saudi Arabia

${ }^{4}$ Al-Azhar University, Cairo, Egypt

"Corresponding author: MI Fatani, Hera General Hospital, Makkah, Saudi Arabia, Tel: 00966555517839; E-mail: m_fatani@yahoo.com

Received date: January 22, 2018; Accepted date: February 15, 2018; Published date: February 22, 2018

Copyright: (C) 2018 Al otaibi HO, et al. This is an open-access article distributed under the terms of the Creative Commons Attribution License, which permits unrestricted use, distribution, and reproduction in any medium, provided the original author and source are credited.

\begin{abstract}
Objective: The objective of this study is to provide the clinical features of infantile hemangiomas and their associated risk factors.

Method: The study included patients who have been diagnosed with infantile hemangiomas, who were identified from a logbook in the Dermatology Department of Hera General Hospital, Makkah, Saudi Arabia. Demographic, prenatal, perinatal, and clinical data, along with complications and treatment modalities, were included on the data sheet.

Result: The medical records of 61 patients were examined. Most of our patients were female (69.9\%) and the maternal age of their mothers ranged from 22 to 43 years, with a mean maternal age of 28.8 years and a median age of 28 years. A positive family history of vascular anomalies in first-degree relatives was reported in $11.5 \%$ of patients. In 58 patients (95.1\%), the age of onset for lesions was before two weeks (86.2\%) and over two weeks $(13.8 \%)$. Complications were noted in eight patients $(13.3 \%)$. Most of our patients were treated by topical betablockers $(39.7 \%)$, followed by pulsed-dye laser $(10.3 \%)$ and systemic propranolol $(10.3 \%)$. Observation of the hemangioma progression was seen in $57.6 \%$ of our patients.
\end{abstract}

Conclusion: Hemangiomas more commonly occur in premature, female infants, who are more likely to be born as a product of single gestation. Further studies are needed to define other risk factors and to understand the relationship between potentially confounding factors.

Keywords: Infantile hemangiomas; Makkah

\section{Introduction}

There are two main types of vascular lesion in an infant: vascular malformations and tumors [1]. Hemangiomas, also known as strawberry birthmarks, are the most common vascular tumors of infancy [2], yet surprisingly the actual incidence of infantile hemangiomas remains unknown [3]. Some studies have reported that the incidence of hemangiomas is up to $2.6 \%$ of neonates and up to $12 \%$ of children by the first year [4].

Hemangiomas are soft, bright, red marks over the skin [5] and are a type of benign endothelial cell neoplasm. They usually appear in the first few days to months of life [6]. Infantile hemangiomas are often characterized by two subsequent phases: a growth phase in the first year of life, followed by an involution phase over the next 5-7 years or more [4].

The cause is unknown but different factors are found to influence infantile hemangiomas, such as family history, gender, race, preterm status, and low birth weight, as well as whether an infant is the product of multiple gestations or born to older mothers. These factors have been explored in many studies [7] and may provide clues to their pathogenesis. The role of genetics in IH is only partially understood. Most IHs occurs sporadically. Familial clustering has been reported, even though genetic predisposition is controversial [8]. Evidence exists that some IHs are inherited [9]. Walter et al reported 6 pedigrees with an autosomal dominant inheritance of high penetrance; for 3 , linkage to chromosome 5q31-33 was proposed [10]. In a small number of patients, genetic variants were associated with germ line mutations in the VEGFR2, VEGFR3 and TEM8 genes; these genes regulate major angiogenesis-signaling pathways, suggesting hyper activation of VEGFR2 signaling in the pathogenesis of IH $[11,12]$.

Infantile hemangiomas are often benign with a self-limited course [13]. However, in some cases they may cause complications such as permanent disfigurement and ulceration, which can lead to pain, bleeding, scarring, and infection [14]. The diagnosis of infantile hemangiomas is usually based on the clinical appearance of the lesions.

Although hemangiomas can appear on any part of the body, previous studies have demonstrated that they are more commonly located in the head and neck area [15]. Most are proliferate and involute without any functional impairment, but a minority require some form of intervention. Both the medical and psychological impact should be taken into consideration when a hemangioma is located on a patient's face [7]. This is because it will be more severe medically and 
Citation: Al otaibi HO, Fatani MI, Alshareef MM, Khalifa MA, Mohammed SS (2018) A Retrospective Study of Infantile Hemangiomas: Demographic and Clinical Characteristics at Hera General Hospital, Makkah, Saudi Arabia. J Dermatol Dis 5: 270. doi: $10.4172 / 2376-0427.1000270$

Page 2 of 4

may require an intervention if it develops and compresses on the vital organ [13].

In the past, the treatment options for infantile hemangiomas were limited and their potential side effects were considerable. Now, however, there are many treatment options of infantile hemangioma, although debate continues about the best strategies for its management. In 2011, a Cochrane analysis of interventions for infantile hemangiomas showed that there is a limitation in the ability to identify the single best treatment due to non-availability of clinical trials and the absence of medication approved by the US Food and Drug Administration for the treatment of infantile hemangiomas [5].

Our objective for this study is to provide the clinical features of infantile hemangiomas and their associated risk factors in the Makkah region of Saudi Arabia, in order to advance our knowledge of it in our population.

\section{Methodology}

The study included patients who were diagnosed with infantile hemangiomas from a logbook in the Dermatology Department of Hera General Hospital. The datasheet included demographic, prenatal, perinatal and clinical data, along with information about complications and treatment modalities.

Statistical analysis was carried out using SPSS 13.0. The data were evaluated using descriptive statistical methods (mean \pm standard deviation, median, frequencies and percentages). For all continuous factors, a univariable analysis was performed using chi-squared tests. A two-tailed $\mathrm{P}$ value less than 0.05 was considered statistically significant.

\section{Results}

The medical records of 61 patients were examined. Most of our patients were female (69.9\%), and the female-to-male ratio was 2:1. The majority of our patients (47.5\%) were the product of spontaneous vaginal delivery, whilst $32.8 \%$ were delivered by cesarean section and $3.3 \%$ by ventouse delivery.

Data on gestational age were available for 51 patients, $31.1 \%$ of whom were born prematurely (defined as younger than 37 weeks gestational age) and $49.2 \%$ who were full term. The mean birth weight was $2473 \mathrm{~g}$ and the median birth weight was $2550 \mathrm{~g}$. Data on birth weight were available for 46 patients, $23.9 \%$ were very low birth weight (defined as $1500 \mathrm{~g}$ ), 23.9\% were low birth weight (defined as 1500-2499 g) and 52.2\% were normal birth weight (defined as $2500 \mathrm{~g}$ and more). The correlation between prematurity and low birth weight was statistically significant (P-value 0.009).

Forty infants (65.6\%) were products of single gestations and 19.7\% of multiple gestations. A positive family history of vascular anomalies in first-degree relatives was reported in seven patients (11.5\%). The age of the patients' mothers ranged from 22 to 43 years, with a mean maternal age of 28.8 years $(S D \pm 5.8)$ and a median age of 28 years. The average maternal age of first-time mothers was 26.5 years.

In 58 patients (95.1\%), the age of onset for lesions usually occurred before two weeks (86.2\%) but also could occur at two weeks and over (13.8\%).

Among data available for 55 patients, the most common site of hemangioma was seen in the face (36.4\%). Other locations included upper limbs (18.3\%), lower limbs (12.7\%), chest (12.7\%), scalp (9.1\%) and $3.6 \%$ for each neck, back, and buttock.
A total of $88.5 \%$ of our patients presented with a solitary lesion and $11.5 \%$ with multiple lesions. Complications were noted in eight patients $(13.3 \%)$, including ulceration in $9.8 \%$ of patients, infection in $1.6 \%$, and other complications in $1.6 \%$.

Treatment was administered to 36 patients (62.1\%), with five being treated with systemic steroids (8.2\%), 23 with topical beta-blockers (39.7\%), six with pulsed-dye laser (10.3\%), and six with systemic propranolol (10.3\%). Hemangioma progression was seen in $57.6 \%$ of our patients.

\section{Discussion}

Infantile hemangiomas are the most common vascular tumors of childhood, affecting about $5 \%$ of all infants. In this small group of patients, we systematically collected demographic, prenatal, perinatal, and clinical data on infants with hemangiomas to identify significant trends of the disease, including the different treatment modalities.

The female to male ratio was $2: 1$, which is comparable with the previously published ratio that ranges from $1.4: 1$ to $3: 1$ [16-19]. The reason for female predominance is unclear. Kindred studies have suggested that a subset of hemangiomas may be inheritable and linked to genes on chromosome 5 [20]; no genetic mutations on the $\mathrm{X}$ chromosome have been reported. Historically, some researchers have argued that parents perceive hemangiomas to pose a greater cosmetic concern when females are affected, which could be a reason why girls are over-represented in dermatology clinics.

Most of our patients (47.5\%) were the product of spontaneous vaginal delivery, although $32.8 \%$ were delivered via cesarean section and $3.3 \%$ by ventouse delivery, which is less than the published data, which showed $20 \%$ in the population study [15].

The correlation between prematurity and low birth weight was statistically significant (P-value 0.009) for our patients, which is comparable with one published study [21]. It is unclear whether the presence of hemangioma places the infants at risk of prematurity or vice versa. It is possible that an imbalance of angiogenic control mechanisms may result from prematurely removing a developing fetus from maternal and placental influences [21].

In our study, $47.8 \%$ of the patients were low birth weight, defined as $\leq 2500 \mathrm{~g}$, which is more than one population-based study (12\%) [15]. This could be explained by the fact that our research is a hospital-based study, in which the number of patients included is expected to be more than in a population-based study.

Most of our patients (65.6\%) were the product of a single gestation, and $19.7 \%$ were the product of multiple gestations. This finding is comparable with another study in which the number of infants of multiple gestations was $10.6 \%$ [21].

Infantile hemangioma lesions range from a few millimeters to several centimeters in diameter. Most of our patients presented with solitary lesions (88.5\%), with only $11.5 \%$ of them suffering multiple lesions, which is less than the data published in one study [21]. This may be due to a limited number of cases in our study.

In one published study [22], the authors found that $51 \%$ of their patients had complications, including ulceration (13\%) and infections (11\%). This is a greater amount of incidences than we found, as $9.8 \%$ and $1.6 \%$ of our patients suffered ulceration and infection, respectively. This difference could be explained by the fact that the aim of the other research was to identify complications in hemangioma patients. 
Citation: Al otaibi HO, Fatani MI, Alshareef MM, Khalifa MA, Mohammed SS (2018) A Retrospective Study of Infantile Hemangiomas: Demographic and Clinical Characteristics at Hera General Hospital, Makkah, Saudi Arabia. J Dermatol Dis 5: 270. doi: $10.4172 / 2376-0427.1000270$

Page 3 of 4

In our study, the majority of hemangiomas were located on the face (36.4\%), which differs from the findings of another study [17] that reported the trunk as the most frequent site in a population-based study [15].

Systemic corticosteroids have become a mainstay in the treatment of hemangiomas, yet their mechanism of action is not well understood $[23,24]$. Daily doses of $2-3 \mathrm{mg}$ of prednisolone or prednisone per kilogram of body weight are usual and were prescribed to our patients, although some investigators have recommended even higher doses (5 $\mathrm{mg} / \mathrm{kg}$ daily).

Systemic steroid treatment results in dramatic shrinkage of the hemangioma, usually within days, in an estimated one-third of infants. In another third, stabilization of the growth without measurable shrinkage is observed and minimal or no response is similarly found in a further third [24], which also applied to our cases. Despite many potential side effects, including irritability, gastrointestinal upset, immunosuppression, hypertension, and growth retardation, systemic steroid treatment remains useful in some instances of hemangioma, particularly in patients who cannot tolerate other therapeutic options.

Propranolol therapy has become increasingly more helpful in the management of infantile hemangioma. Leaute-Labreze et al. [25] fortuitously discovered the efficacy of beta-blockers for the treatment of infantile hemangioma in 2008. A few of our patients (10.3\%) used this medication, which led to stabilization of the hemangioma. The usefulness of this drug is shown in more than 170 reports and studies $[26,27]$.

Topical agents are an appropriate therapy for use on small, thin lesions, but whilst the side effects are less than systemic agents, there is limited data about the efficacy. Twenty three of our patients $(39.7 \%)$ used topical beta-blockers. Timolol maleate is a non-selective topical beta-blocker that has been approved for the treatment of ocular glaucoma and hypertension in children and infants by the Food and Drug Administration [28]. For our patients, we selected the ophthalmic preparation of timolol maleate, which has been used in other studies as a topical treatment of infantile hemangioma. To date, the only adverse effect reported in association with this treatment is a single episode of severe sleep disturbance. Nonetheless, experts urge caution with the drug and recommend using no more than one drop twice a day on affected lesions [29].

Several laser systems have been used to treat hemangiomas. The flash lamp-pumped pulsed-dye laser, though extremely useful in treating port-wine stains, is less efficient for hemangiomas. Only $10.3 \%$ of our patients were treated with a pulsed-dye laser, which showed only mild improvement. This is because of the limited depth of penetration (approximately $1 \mathrm{~mm}$ ), meaning that this laser works better for thin superficial hemangiomas than for those that are destined to be both superficial and deep [30]. However, the laser can be used to improve residual telangiectasia after involution and is useful in treating ulcerated hemangiomas, resulting in decreased pain and prompt reepithelialization [31].

\section{Conclusion}

We find that hemangiomas more commonly occur in premature, female infants who are the product of single gestation. More studies are needed to define further the risk factors and complications for hemangiomas and to understand the relationship between potentially confounding factors.

\section{References}

1. Enjolras O, Mulliken JB (1997) Vascular tumors and vascular malformations (new issues). Adv Dermatol 13: 375-423.

2. Bruckner AL, Frieden IJ (2003) Hemangiomas of infancy. J Am Acad Dermatol 48: 477-493.

3. Kilcline C, Frieden IJ (2008) Infantile hemangiomas: How common are they? A systematic review of the medical literature. Pediatr Dermatol 25: 168-173.

4. Alsuwaidan SN (2012) PHACES syndrome in association with airway hemangioma: First report from Saudi Arabia and literature review. Ann Thorac Med 7: 44.

5. Leonardi-Bee J, Batta K, O'Brien C, Bath-Hextall FJ (2011) Interventions for infantile hemangiomas (strawberry birthmarks) of the skin. Cochrane Database Syst Rev.

6. Jacobs AH (1957) Strawberry hemangiomas: The natural history of the untreated lesion. Calif Med 86: 8-10.

7. Chen TS, Eichenfield LF, Friedlander SF (2013) Infantile hemangiomas: An update on pathogenesis and therapy. Pediatrics 131: 99-108.

8. Greco MF, Frieden IJ, Drolet BA (2016) Infantile hemangiomas in twins: A prospective cohort study. Pediatr Dermatol 33: 178-183.

9. Grimmer JF, Williams MS, Pimentel R (2011) Familial clustering of hemangiomas. Arch Otolaryngol Head Neck Surg 137: 757-760.

10. Walter JW, Blei F, Anderson JL, Orlow SJ, Speer MC, et al. (1999) Genetic mapping of a novel familial form of infantile hemangioma. Am J Med Genet 82: 77-83.

11. Boon LM, Ballieux F, Vikkula M (2011) Pathogenesis of vascular anomalies. Clin Plast Surg 38: 7-19.

12. Jinnin M, Medici D, Park L (2008) Suppressed NFAT-dependent VEGFR1 expression and constitutive VEGFR2 signaling in infantile hemangioma. Nat Med 14: 1236-1246.

13. Haggstrom AN, Drolet BA, Baselga E, Chamlin SL, Garzon MC, et al. (2006) Prospective study of infantile hemangiomas: Clinical characteristics predicting complications and treatment. Pediatrics 118: 882-887.

14. Drolet BA, Esterly NB, Frieden IJ (1999) Hemangiomas in children. N Engl J Med 341: 173-181.

15. Hoornweg MJ, Smeulders MJ, Ubbink DT, van der Horst CM (2012) The prevalence and risk factors of infantile haemangiomas: A case-control study in the Dutch population. Paediatr Perinat Epidemiol 26: 156-162.

16. Bree AF, Siegfried E, Sotelo-Avila C, Nahass G (2001) Infantile hemangiomas: Speculation on placental trophoblastic origin. Arch Dermatol 137: 573-577.

17. Finn MC, Glowacki J, Mulliken JB (1983) Congenital vascular lesions: clinical application of a new classification. J Pediatr Surg 18: 894-900.

18. Bivings L (1954) Spontaneous regression of angiomas in children: twentytwo years' observation covering 236 cases. J Pediatr 45: 643-647.

19. Hidano A, Nakajima S. Earliest features of the strawberry mark in the new-born. Br J Dermatol 87: 138-144.

20. Berg JN, Walter JW, Thisanagayam U, Evans M, Blei F, et al. (2001) Evidence for loss of heterozygosity of $5 \mathrm{q}$ in sporadic haemangiomas: Are somatic mutations involved in hemangioma formation? J Clin Pathol 54: 249-252.

21. Haggstrom AN, Drolet BA, Baselga E, Chamlin SL, Garzon MC, et al. (2007) Prospective study of infantile hemangiomas: Demographic, prenatal, and perinatal characteristics. J Pediatr 150: 291-294.

22. Akcay A, Karakas Z, Saribeyoglu ET, Unuvar A, Baykal C, et al. (2012) Infantile hemangiomas: Complications and follow-up. Indian Pediatr 49: 805-809.

23. Frieden IJ (1997) Management of hemangiomas. Pediatr Dermatol 14: 757-783.

24. Enjolras O, Riche MC, Merland JJ, Escande JP (1990) Management of alarming hemangiomas in infancy: A review of 25 cases. Pediatrics 85: 491-498. 
Citation: Al otaibi HO, Fatani MI, Alshareef MM, Khalifa MA, Mohammed SS (2018) A Retrospective Study of Infantile Hemangiomas: Demographic and Clinical Characteristics at Hera General Hospital, Makkah, Saudi Arabia. J Dermatol Dis 5: 270. doi: $10.4172 / 2376-0427.1000270$

Page 4 of 4

25. Léauté-Labrèze C, Dumas de la Roque E, Hubiche T, Boralevi F, Thambo JB, et al. (2008) Propranolol for severe hemangiomas of infancy. N Engl J Med 358: 2649-2651.

26. Sans V, de la Roque ED, Berge J, Grenier N, Boralevi F, et al. (2009) Propranolol for severe infantile hemangiomas: Follow-up report. Pediatrics 124: e423-e431.

27. Buckmiller L, Dyamenahalli U, Richter GT (2009) Propranolol for airway hemangiomas: A case report of a novel treatment. Laryngoscope 119: 2051-2054.

28. Coppens G, Stalmans I, Zeyen T, Casteels I (2009) The safety and efficacy of glaucoma medication in the pediatric population. J Pediatr Ophthalmol Strabismus 46: 12-18.
29. McMahon P, Oza V, Frieden IJ (2012) Topical timolol for infantile hemangiomas: Putting a note of caution in "cautiously optimistic". Pediatr Dermatol 29: 127-130.

30. Garden JM, Bakus AD, Paller AS (1992) Treatment of cutaneous hemangiomas by the flash lamp-pumped pulsed dye laser: A prospective analysis. J Pediatr 120: 555-560.

31. Morelli JG, Tan OT, Yohn JJ, Weston WL (1994) Treatment of ulcerated hemangiomas in infancy. Arch Pediatr Adolesc Med 148: 1104-1105. 